\title{
THE BABADOOK DE JENNIFER KENT: LA DUALIDAD DEL SER HUMANO Y LA ESCENIFICACIÓN DEL MONSTRUO
}

\author{
Jesús Fernando Diamantino Valdés \\ jesus.diamantino@uai.cl \\ Carolina María Teresa Heiremans \\ carolina.heiremans@uai.cl \\ Universidad Adolfo Ibáñez (Chile)
}

Recibido: 02-07-2015

Aceptado: 20-11-2015

(c) (1)

RESUMEN

En el presente estudio, se demostrará cómo la dimensión monstruosa, siempre latente en el inconsciente colectivo e individual, se transforma en una criatura que encarna la irracionalidad desde la infancia. Para ello se analizará la película The Babadook (2014) de Jennifer Kent, tomando en consideración la intertextualidad con la tradición folclórica y las estrategias discursivas que denotan lo fantástico, como la metaficción y el cronotopo pesadillesco.

Palabras claves: Monstruo, infancia, tradición folclórica, cronotopo, metaficción.

\section{Abstract}

The objective of this paper is to demonstrate how the dimension of monstrosity, ever latent in the individual and collective subconscious, transforms itself into a creature who incarnates the irrationality within childhood. To demonstrate this, the film directed by Jennifer Kent, The Babadook (2014), will be analyzed from the perspective of the intertextual dialogue that it establishes with the folklore tradition and the discursive strategies that denote the fantastic genre, such as metafiction and the nightmare chronotope.

KEY WORDS: Monster, childhood, folklore, chronotope, metafiction. 
SOBRE LA DUALIDAD

Ser madre ha sido uno de los principales anhelos y motivo de realización de muchas mujeres desde tiempos inmemorables. Esta afirmación, que parece incuestionable, ha quedado plasmada en diversas figuras femeninas que aluden a la fertilidad y al culto a las Magna mater o Diosas madre, extendido desde hace más de 30.000 años. Pero este amor incondicional que muchas declaran sentir por los hijos al igual que la permanente preocupación y constante entrega, no son inquebrantables. Tanto en la literatura como en el arte es posible encontrar indicios de una dualidad que caracteriza al ser humano, donde lo bueno y lo malo coexisten y cuyo lado sombrío, en determinados momentos, ha logrado terminar con la preciada relación madre-hijo.

Este monstruo, que todo hombre lleva dentro, ha sido motivo de inspiración para mitos, cuentos populares y de terror, que dan vida a uno de los principales miedos ancestrales.

En The Babadook, se narra la historia de una madre que tiene que criar sola a su único hijo. Tras fallecer su esposo Oskar en un accidente automovilístico, cuando la estaba llevando al hospital precisamente para dar a luz, Amelia debe hacerse cargo de la educación y bienestar de Samuel. Este pequeño, de 6 años, con algunos problemas de conducta, adora la magia, los cuentos de hadas y, al igual que la mayoría de los niños de esa edad, teme a los monstruos imaginarios que se ocultan bajo su cama, en el armario y en los rincones más oscuros de su habitación. Hasta que una noche, después de que Amelia comenzara a leerle la historia de Mister Babadook, uno de los tantos libros en el estante de cuentos, comienzan a suceder una serie de hechos extraños. Samuel empieza a fabricar armas caseras para combatir aquella misteriosa criatura, de la que nadie puede deshacerse después de darse cuenta de que sí existe.

«La vida puede ser muy engañosa y no siempre es lo que parece». Con esta frase, que Samuel repite en tres oportunidades a lo largo de la película, cada vez que presenta su espectáculo de magia, se deja entrever la realidad de muchas personas que, día a día, tratan de ocultar una vida llena de frustraciones y donde prevalece la desesperanza. Y es eso precisamente lo que caracteriza a Amelia, quien después de reprimir por casi siete años un profundo dolor que la carcome, se dejará llevar por la impotencia y la rabia para engendrar una criatura de la que solo Samuel está plenamente consciente. Tanto es así que la frase predilecta de Mister Babadook es: «mientras más me niegues, más fuerte me hago».

Amelia es rechazada por una sociedad que siente compasión por ella porque es viuda y tiene que «soportar» a un niño malcriado, hecho que le 
enrostra Claire, su propia hermana. Asimismo, ha vivido su maternidad totalmente sola, tarea que la obligó a postergar su realización profesional como escritora. Por otra parte, su entorno niega sus teorías acerca de que «algo o alguien» la está acechando al igual que a su hijo, cuando acude a la policía para denunciar esta persecución de la que es objeto. Poco a poco, este mundo que le es hostil la presiona para que libere a «The Babadook», aquel monstruo que lleva dentro, pero que la razón es capaz de controlar. Ese lado oscuro que se oculta y que siempre estuvo presente en la literatura y en la tradición pictórica, ${ }^{1}$ hoy en día, también lo está en el cine, como una manifestación más de la dualidad del ser humano.

Sin duda alguna, lo que más llama la atención en esta película es el libro Mister Babadook. Con una tapa roja, que se asemeja al color de la sangre, y con un título en letras negras, aparece, una y otra vez, aunque Amelia intente deshacerse de este: escondiéndolo en la repisa de un clóset, rompiéndolo en pedazos y, finalmente, quemándolo. Aquellas hojas que solían estar en blanco, se llenan de ilustraciones que reflejan los temores ocultos, primero de Samuel, pero conforme transcurre la historia, también de Amelia, una mujer, que tras liberar su monstruo interno, se atreve a confesar que hubiese querido que muriese su hijo y no su marido, que sueña con tener más tiempo libre y a solas, y que está frustrada porque ya no puede escribir artículos y cuentos para niños; en definitiva, es quien crea Mister Babadook, un inocente relato infantil, que pone de manifiesto la verdadera función terapéutica que cumplen los cuentos populares, y que fue ampliamente analizada por el psiquiatra infantil Bruno Bettelheim (2012), en su libro Psicoanálisis de los Cuentos de Hadas.

\section{Cuentos y Mitos POPUlaRes}

«Los mitos constituyen literalmente el tesoro más precioso de la tribu. Se refieren al núcleo de lo que la tribu venera como su cosa más sagrada. Los mitos más importantes solo los conocen los ancianos, que guardan celosamente su secreto» (1931: 526). Estas palabras de Lévy-Bruhl dan cuenta de la importancia del mito, que es parte esencial del ritual mágico de antaño. Una vez rota la prohibición de ser contados, habrían derivado en los denominados cuentos populares. Sin embargo, Antonio Rodríguez Almodóvar asegura que existen motivos suficientes para pensar que muchos relatos literarios de tipo tradicional se basan en la misma universalidad que tiene el mito.

1 Al respecto, resultan sumamente sugestivas obras como Venus frente al espejo (1599-1660) de Velázquez o La pesadilla (1781) de Johann Heinrich Füssli. 
En la medida que los cuentos populares se fueron transmitiendo de generación en generación, gran parte de esta poética de la tradición oral cobijó los principales temores y conflictos del hombre, que surgieron con la Revolución Neolítica y que son el resultado de las contradicciones que se generaron en el tránsito de la sociedad tribal cooperativa y endogámica, nómada o seminómada, a la sociedad agrícola estamentaria, basada en la propiedad privada hereditaria del mundo indoeuropeo (Rodríguez Almodóvar, 2004). Pero también es posible encontrar en otras latitudes el mismo motivo central de un cuento o de un mito, pero con un inicio o final distintos. Tal es el caso de «La Cenicienta», que podemos rastrear desde el antiguo Egipto hasta la China y del que M.R. Cox ha recopilado 345 versiones, todas consideradas auténticas formas de expresión popular.

De su formación arcaica, los cuentos populares, sobre todo, los maravillosos, conservarían ciertos ritos, como los de iniciación y de relaciones con los antepasados, que ponen de manifiesto la importancia de la muerte, entre otros tópicos. Y es precisamente esta inquietud o temores ancestrales los que se ven plasmados en la película The Babadook. Amelia crea este libro y junto con liberar su monstruo interno, va plasmando, inconscientemente, su rabia, sus deseos más ocultos en una serie de ilustraciones terroríficas que predicen la muerte de sus seres más cercanos. Es cierto que en un comienzo este misterioso libro prometía entretener a Samuel con las historias de Mister Babadook, pero podemos ver que, poco a poco, esa función terapéutica que cumplen los cuentos maravillosos en los niños, cede su lugar a la madre.

Para Rodríguez Almodóvar, en estos cuentos predomina una dimensión simbólica que ayuda a los pequeños a configurar una cierta cosmogonía o primera imagen del mundo: "La base de la denominada pedagogía "natural" del folclore se encuentra en el desarrollo de la función evocativa del lenguaje [...] de aprendizaje a través de imágenes o secuencias narrativas laboriosamente construidas, de perfiles fuertes y conflictos tremendos, que esconden otras y otras lecturas, y que la mente laboriosa del niño ha de descubrir» (2008: 5).

Samuel siempre supo que en algún minuto Mister Babadook despertaría y que su madre tendría que luchar contra él. Incluso se lo anticipa con frases como: «No lo dejes entrar», «cuando se coma tu interior, estarás asustada» o «no quiero que nada malo te suceda». Pero este proceso de liberación lento y continuo llega a su clímax cuando Amelia ve en el libro cómo mata a su propio hijo.

Este tópico no es nuevo en la literatura. Basta recordar el mito de Jasón, donde Medea, nieta del mismo Sol, traiciona a su propio linaje y familia, con 
tal de casarse con su amado. Lo ayuda a superar una serie de pruebas que Eetes le da antes de que pueda penetrar en el bosque sagrado y robar el vellocino de oro, custodiado por un dragón. Pero Jasón olvidará esta promesa de matrimonio, a pesar de los hijos habidos con Medea, quien fingirá aceptar la boda con Glauca, hija del rey Corinto, y los envenenará con suntuosos regalos. Desesperada, Medea no dudará en degollar a sus propios hijos y emprenderá un viaje del que nunca regresará. Esa falta de cordura también la experimenta Amelia, quien no ha podido olvidar a su marido y necesita vivir su duelo.

Desde una perspectiva psiquiátrica, se podría especular que presenta todos los síntomas de un trastorno obsesivo compulsivo, con alucinaciones, momentos intensos de angustia, falta de sueño e irritabilidad, entre otros. Pero no se puede encasillar ni darle nombre a una criatura que protagoniza la eterna lucha del mal contra el bien, de lo irracional frente a lo racional y que es intrínseca al ser humano.

Rodríguez Almodóvar, quien ha trabajado en una nueva definición de «cuento popular», señala que este es: «un relato de ficción que solo se expresa verbalmente y sin apoyos rítmicos; carece de referentes externos, se transmite principalmente por vía oral y pertenece al patrimonio colectivo» (2010: 3).

Detengámonos en este último concepto: patrimonio colectivo. Todos los cuentos populares custodian un tesoro que es universal y que tenemos que transmitir y preservar a lo largo de los años. Resguardan nuestros temores, nuestros conflictos, nuestra dualidad como seres humanos y, hoy en día, también están presentes en películas como The Babadook.

\section{EL MONSTRUO METAFICCIONAL}

Lovecraft, en su canónico ensayo El horror sobrenatural en la literatura, señaló que lo que define realmente al verdadero cuento de terror es «saber si suscita o no en el lector un hondo sentimiento de espanto al contacto de unos elementos y fuerzas desconocidos; una actitud sutil de acecho pleno de espanto, como si se estuviera escuchando el latido de unas alas tenebrosas o el zumbido de unas formas y unos seres en el limbo más remoto del universo conocido» (Lovecraft, 1973: 455). Esta experiencia receptiva que sustenta a través de la ruptura del universo intertextual y el desmoronamiento fugaz de las convicciones del lector (en este caso, espectador), definen estéticamente la experiencia fantástica. El Babadook, produce aquel quiebre irracional a través de dos mecanismos narrativos: la metaficcionalidad y el cronotopo pesadillesco. 
En el cine fantástico, el monstruo infantil pareciera ser el leit motive más recurrente de todos, particularmente la asociación del niño con la imaginación terrorífica, la cual otorga amplias posibilidades a la Industria. Al carecer de limitaciones morales y barreras socioculturales definidas, el universo infantil se ha convertido en un caldo de cultivo para exteriorizar los miedos más profundos del hombre; en cuyo universo lo irracional pareciera no tener cabida. The Babadook es consecuencia de una amplia tradición fílmica relacionada con la figura del asustador. A lo largo de la historia y en diferentes partes del mundo, aquel miedo ha adoptado diversas máscaras y denominaciones: Bogeyman, Coco, Sandman, El hombre del saco, etc; personajes de la cultura popular que tienen como objetivo aterrorizar (o adoctrinar) a los niños para erradicar conductas indeseadas. En la tradición literaria y cinematográfica, los asustadores se materializan a través de ideas ominosas que entroncan con el pavor a la muerte y el aniquilamiento. Los monstruos de estas ficciones conducen a los personajes al desamparo primitivo, los enfrenta a su vulnerabilidad oculta bajo los cimientos de la globalización y la racionalidad.

Jennifer Kent reactualiza aquel paradigma gracias al discurso metalingüístico, que implica no solamente la apropiación de un modelo genérico del cine de terror (el monstruo que acecha en la oscuridad de la habitación), sino también una reflexión sobre el arte y la representación de la imagen. En este sentido, la figura de Mr. Babadook establece un conflicto entre lo sobrenatural y la creación simbólica de los personajes, ya que el libro de donde emerge supuestamente el monstruo no tiene un origen claro. Al respecto se pueden barajar dos posibles interpretaciones: la primera, y más evidente, es que el monstruo sea una proyección de los miedos de la mujer viuda y la repulsión hacia su vástago, pero también no deja de ser sugerente la idea de que el arco argumental de base sea parte de una historia aún más global, es decir, la extensión de un relato macro. Resulta interesante, no solo visualmente, que el formato del texto infantil sea el pop-up book, ya que la interacción entre imagen y texto se sostiene gracias a la vitalidad de las ilustraciones. Esto permite asimilar el libro como un cuerpo somático que se construye en la medida que el lector se adentra en la historia. Dicho proceso cognitivo es similar al que experimentamos como espectadores del film, pues la narratividad de Kent cobra sentido en la medida en que las imágenes del relato infantil se trasmutan a la realidad intratextual de los personajes. He ahí la convergencia de dos mundos que se entrelazan orgánicamente, pero que al mismo tiempo manifiesta una oposición ante las convicciones y la epistemología del lector-espectador; fenómeno que «se puede percibir como un choque entre dos códigos semióticos en 
teoría opuestos el uno al otro: se sugiere la presencia de un elemento irracional en nuestro universo, y por lo tanto se oponen abiertamente el código semiótico de la realidad y el de lo irracional» (Ferreras, 2000: 22). Los acontecimientos no se materializan a partir de las imágenes, sino todo lo contrario. El deterioro psicológico de Amelia y su lucha simbólica con el monstruo llena los vacíos del texto para articular finalmente una sola historia.

\section{EL DESCENSO AL SÓTANO}

Según Mijail Bajtin, el cronotopo se define como «La intervinculación esencial de las relaciones temporales y espaciales asimiladas artísticamente en la literatura (...) En el cronotopo literario-artístico tiene lugar una fusión de los indicios espaciales y temporales en un todo consciente y concreto» (Bajtin, 1986: 11-12). En otras palabras, el concepto alude a la idea de que el tiempo y el espacio se condensan de forma artística, determinando el argumento y el desarrollo narrativo. De esta forma se manifiesta la materia sustancial de la obra, en donde se determina al hombre y su cultura. El mundo configurado por la ficción, cobra sentido solo con el dinamismo del cronotopo. En el cine fantástico de horror, la unidad espacial cobra vital importancia para lograr el efecto estético macabro en cuanto a la asociación de lo sobrenatural con ciertos elementos materiales.

Si en la literatura gótica del siglo XVIII el castillo medieval cobijó los primeros monstruos de la ficción fantástica, ocultando un grotesco espectáculo de violencia y perversidad, el cine de terror contemporáneo hereda de aquel subgénero el tópico de la «casa encantada», lugar que alberga aquellos horrores aquietados por el vértigo capitalista y la seguridad tecnologizada. En este nuevo contexto, la verosimilitud del horror será factible siempre y cuando lo sobrenatural dialogue con aquellos elementos domésticos que recogen el horror ominoso; espacios de sombras y que se asocian, paradójicamente, con un locus de resguardo o marginalidad: la habitación y el sótano.

El siguiente relato del escritor chileno, Diego Muñoz Valenzuela, titulado «Debajo de la cama», podría quizás respaldar lo anterior:

Vio las garras asomándose bajo la cama, pero no dijo nada. Eran grandes, oscuras, ominosas, capaces de desgajar el cuerpo de un hombre grande. Él era un niño, no hacía falta aquel despliegue de terror. Se mordió los labios para desvestirse y ponerse el pijama. Tuvo cuidado de no rozar aquellas garras. Temblando se introdujo al lecho con lentitud; no deseaba perturbar al ente. La madre se asomó por la puerta, le preguntó si tenía frío. Pensó en contestar que 
tenía miedo, no frío. No se atrevió. Lo habían reñido demasiado por imaginar esa clase de cosas. La madre apagó la luz y vino la oscuridad, más no el silencio. (2011: 109)

La cama presenta dos dimensiones: la superior y la inferior. La primera connota lo apolíneo, lo armónico, la luz, lo racional; mientras que «debajo de la cama», proyecta una dimensión sobrenatural gracias al ocultamiento. Así como en Poltergeist (1982) de Tobe Hopper el armario representa el acceso hacia una dimensión pavorosa e inconsciente (el vientre materno para algunos, el infierno para otros), en The Babadook el guardarropa es el acceso a la dimensión ficcional del libro, la prolongación imaginativa de los personajes. Del mismo modo, el sótano (como un infierno dentro de la aparente armonía suburbana), se convierte finalmente en el hogar del monstruo. Dicho desplazamiento responde a la aceptación del Babadook como figura metaficcional, logrando de esta forma unificar un gran escenario narrativo que ya no admite quiebres en su lógica.

De esta forma, The Babadook nos recuerda que la monstruosidad no es más que un reflejo de los conflictos humanos, y que la fantasía o lo sobrenatural son representaciones simbólicas del inconsciente. El cine fantástico es una respuesta a estas inquietudes socioculturales que se mantienen soterradas por las dinámicas de poder y la delimitación de los miedos. Es así como una nueva generación de cineastas (Guillermo del Toro, James Wan, Bryan Murphy, etc.) han reactualizado la semanticidad de la imagen y la narratividad tradicional en el lenguaje fílmico, haciendo eco de los patrones que persisten en la conciencia histórica y que sustentan los miedos contemporáneos. He ahí el porqué de la exposición de los tabúes sexuales, el infanticidio y la locura. Sin duda, una necesaria reflexión sobre la maldad y las relaciones filiales en el siglo xxI.

\section{BibliografÍA}

Bajtín, Mijail (1986): Problemas literarios y estéticos, Editorial Arte y Literatura, La Habana.

Bettelleim, Bruno (2012): Psicoanálisis de los cuentos de hadas, Crítica, Barcelona. FERreras, Daniel (2000): Lo fantástico en la literatura y el cine, VOSA SL, Madrid.

Kent, Jennifer (2014): The Babadook, Causeway Films, Australia.

LÉvY-BRUHL, Lucien (1931): Le surnaturel et la nature dans la mentalité primitive, Félix Alcan, París. 
Lovecraft, H. P. (1973): Supernatural horror in literature, Dover publications, New York.

MuÑoz Valenzuela, Diego (2011): Las nuevas hadas, Simplemente Editores, Santiago de Chile.

Rodríguez Almodóvar, Antonio (2004): El texto infinito. Ensayos sobre el cuento popular, Fundación Germán Sánchez Ruipérez, Madrid.

- (2008): «Cuentos Populares, Perfectamente Incorrectos», disponible en http:// www.aralmodovar.es/articulos-conferencias/cuentos-populares-perfectamente-incorrectos-65. [28/06/2015].

Rodríguez Almodóvar, Antonio (2010): «Acerca de la Definición de "Cuento Popular"», disponible en http://www.aralmodovar.es/articulos-conferencias/ acerca-definicion-cuento-popular-47 [28/06/2015]. 